\title{
Study on College Interactive Teaching Based on Mobile Network
}

\author{
Li Yiqun \\ Shanghai University of International Business and Economics \\ liyq@suibe.edu.cn
}

\begin{abstract}
Based on the rapid development of mobile network and interactive teaching, this paper focuses on the college curriculum integrated with literature review, survey analysis, case study and empirical analysis methods. Some important factors are pointed out, such as the personalized learning, modular knowledge, interest-oriented guidance and controllable process in promoting the further development of the college interactive teaching based on mobile network.
\end{abstract}

Keywords-mobile network; college curriculum; interactive teaching; evaluation system

\section{INTRODUCTION}

Based on the rapid development of mobile network technology and the deepening of interactive teaching, the way for colleges at home and abroad to conduct interactive teaching are more diversified, including the construction of mobile network teaching platform, which has built a good foundation. The research on this topic combines the construction of mobile network platform with interactive teaching in colleges. On one hand, it expands the application prospect of mobile network teaching platform, and on the other hand, it also promotes the innovation and development of interactive teaching effect in colleges, which have universal values in theoretical analysis and practice guidance [1].

Based on the rapid development of mobile network platform (3G) and terminal equipment (smart phone, tablet PC), mobile network teaching originated from the continuous extension of network curriculum. The understanding of network teaching is also controversial in China. One is the dynamic definition of network teaching such as Ministry of education of Modern Distance Education Resources Construction Committee "Technical specification for the construction of modern distance education resources" defined network teaching as: Network teaching is the combination of teaching contents with teaching activities of a certain subject through the network, which includes two parts: teaching contents organized according to teaching aims and teaching strategies and network teaching environment. The other is the static definition of network teaching, for example "network teaching is the teaching material based on the computer network transmission, processing and communication with a specific teaching content structure, a new carrier of teaching content, and network curriculum mainly relates to teaching content and the design of teaching activity is involved in the teaching content, while network teaching does not include the implementation of teaching and learning." It is clear that the dynamic definition describes the implementation of the entire network teaching process, while static definition describes the content of network teaching and teaching plan. In this thesis, mobile network teaching means combining dynamic definition with static definition. Not only teaching activity should be taken into consideration, but also learners' process of learning should be stressed in particular because of the characteristics of network teaching separation between teachers and students, so the network teaching is the process of students acquire knowledge and experience through the network from the learning environment where teachers design teaching and learning material [2]. And network teaching includes teaching contents organized according to teaching aims and teaching strategies, software tools for supporting network teaching, learning resource, teaching and learning activities in network environment and teachers and students participated in.

Currently there are quite a lot of researches on the design, exploitation and evaluation of mobile network teaching, while there are a few researches on the application mode, application strategy and application effect of mobile network teaching. The ultimate goal is the mobile network teaching is the effective use of the learners, and improving the utilization rate of the mobile network teaching platform is the foundation to achieve this goal. How to use effectively and play the advantages of network curriculum is not a technical problem, but to combine teaching ideas, learning theory with network technology effectively [3].

\section{LITERATURE RESEARCH}

With the continuous development of mobile network, interactive teaching based on mobile network is also progressing. Scholars in China have also been deepening the research, and some achievements have been made. Based on CNKI mobile network, interactive teaching of network teaching the three keywords search to get the change trend of all kinds of journal publications (Figure.1).

This paper is financially supported by the Humanities and Social Science Research Project of Ministry of Education (12YJC880048). 


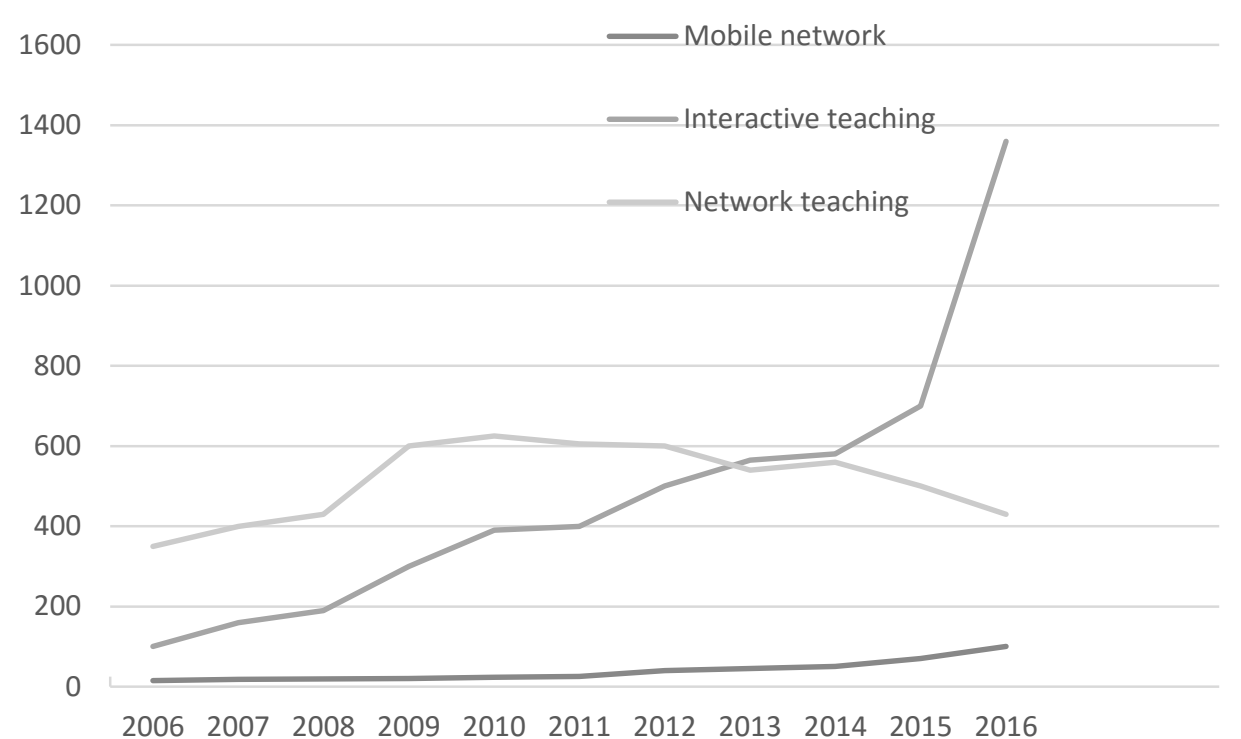

Fig. 1. The number of Journal Papers Published in CNKI(2006-2016)

At present, the research on network teaching has become mature in China, and most of the domestic colleges are using their own network teaching platforms with different features and styles, which have the same characteristics, that is to say they have teaching resources management platform, network teaching management platform and teaching application. However, the design of the teaching mode, teaching method and the network course based on the network teaching platform receive many scholars' universal attention.

Although the number of literatures on mobile network has been increasing, the number has remained in a low level. It can be seen that scholars are not very familiar with the emerging technology for mobile network [4]. And the application of mobile network is immature, which is still in the exploratory stage. On the other hand, it also means there is a big potential and market in mobile network teaching. Especially from 2015 with the emergence of the ideal about WeChat, APP as a teaching platform as well as the promotion of $4 \mathrm{G}$ mobile network makes researches on mobile network become popular.

While there are many researches on the interactive teaching, and the number of literature was a blowout rise, which set off a new wave of research. Especially in the past two years, scholars have become increasingly concerned about the interactive teaching, especially the trial and innovation of interactive mode. The development of universal multimedia technology has made price lower of related products, which promotes interactive teaching methods and makes it popular; Besides with the development of new technology including cloud technology and Internet of Thing technology, the interactive teaching is also welcomed. And the development of mobile network provides a new carrier, which lets interactive teaching possible and receives much attention [5].

With the rapid development of interactive teaching in the field of higher education, there are various researches in the field of higher education in foreign countries, including research reports and certification standards from governments to international agencies. Among them, AACSB has 21 certification standards, mainly including adequate teachers, intelligence level, special needs, the same mission, group learning, extracurricular experts, educational responsibility, student engagement and learning feedback and so on [6].

\section{EMPIRICAL RESEARCH AND ANALYSIS}

This investigation selects students from colleges mostly in Shanghai as samples, mainly adopting the online research and questionnaire, receiving 655 valid questionnaires in total. The investigated students are from 45 universities, including Shanghai University of International Business and Economics, Donghua University, Shanghai University of Engineering Science and Shanghai Institute of Visual Art and other 45 universities. Here are the investigation results. (Figure 2)

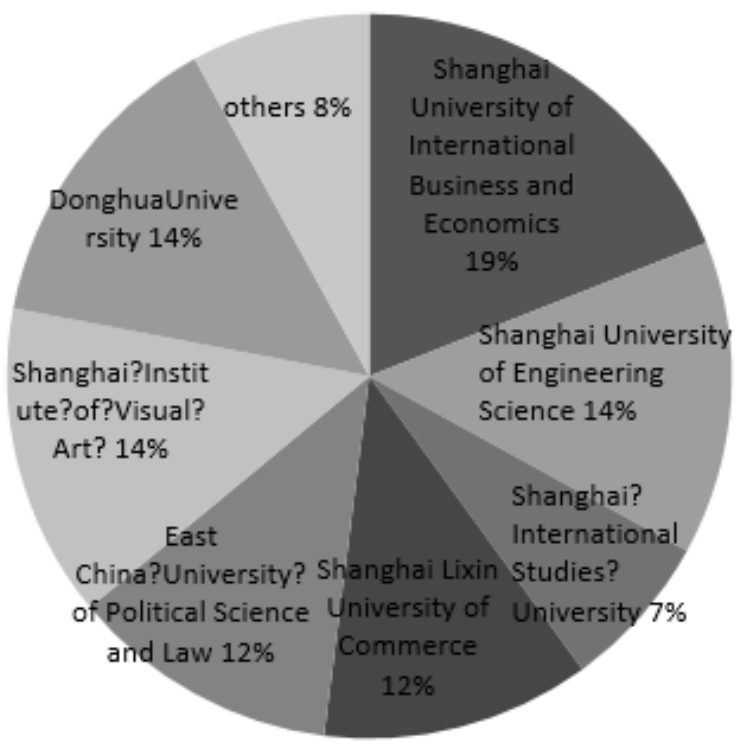

Fig. 2. Proportion of students in colleges based on the research(2015) 


\section{A. Mobile network teaching platform}

In the initial stage of the questionnaire, it mainly does research on whether student participated in the learning on mobile network teaching platform before, among whom there are $68.15 \%$ of people have used it, and $65.12 \%$ of people are willing to use it for learning. For the basis of mobile network teaching platform: mobile network, the research found $54.07 \%$ of people use mobile phone to learn, which reflects there are a large number of people using mobile phone. It also means the prospect in using mobile network teaching platform looks favorable. And it will be further developed in the future. However, according to time data that students use mobile network teaching platform every week, and $45.8 \%$ of students spend $1-5$ hours using it and $42.7 \%$ of students spend less than 1 hour. It shows from this result that the frequency is not high.

In terms of using functions of mobile network teaching platform, the investigation found $64.2 \%$ for self-test, $44.3 \%$ for submitting a job, $42.3 \%$ for resource sharing, and $20.3 \%$ for simulation experience, $17.6 \%$ for notification, $16.6 \%$ for interactive discussion and $9.7 \%$ for course evaluation. By the self-test platform, students can learn online and master their own process of learning at the same time, which helps students control the progress so as to achieve personalized learning. And the function of submitting job is based on the rigid part of school teaching, which reflects that compulsory learning for the college students plays a certain role in promoting the network learning. The disadvantages of interactive teaching on mobile network platform is also obvious. That $29.7 \%$ of students hold the view that the network is slow and this is the largest objective obstacles to mobile network interactive teaching; similarly $29.7 \%$ of students think that the function is faulty because it is very difficult for the teaching platform of the mobile terminal to copy the full functionality of the network teaching platform completely, such as the number of sites visits or job submission; that $45.8 \%$ of students think the platform has a poor stability because the differences in mobile device and its environment, which is easy to make the teaching result unsatisfactory because of the lack of stability of the mobile network; that $28.0 \%$ of students think it is difficult to focus on study, and on one hand it is uneasy to ensure students to study as fully engaged in learning in the class, and on the other hand, in order to have students concentrate highly on mobile-client teachers need to enrich the teaching content.

\section{B. Mobile Network Teaching Model}

In terms of the types of learning course, the investigation found that $53.1 \%$ of people use the mobile network teaching platform for public courses learning and $24.2 \%$ of people for professional learning. In response to this phenomenon, the investigators use the in-depth interview, whose result indicated the reason that why students choose these two types of courses is based on the student's interests. And another reason is that the process of these two courses can be controlled, and courses are modular, also are suitable for interaction and can be learned repeatedly. Meeting students' interests in learning in the process of mobile network teaching is better than in the conventional education. In the in-depth interview, such similar courses including Computer, English and ACCA and so on are the most popular among college students on the mobile network teaching platform, and these three courses have the same characteristics: modularization, that is to say students can choose the sub-modular according to their needs, which is more user-friendly compared to the traditional teaching where learning depends on the progress of teachers' teaching pace.

In terms of learning styles of mobile network teaching, $63.7 \%$ of people choose to learn individually and independently, while $16.8 \%$ of people choose cooperative learning with other students. For more than half of the people choose independent learning, by the in-depth analysis of mobile network teaching platform as an open platform, the investigation found people mentally reject the way of cooperating with unfamiliar people coming from different places. And only $9.5 \%$ of students choose to study with teachers, most of the students said they tend to self-study.

There are many ways in terms of mobile learning mode, including $66.7 \%$ for multimedia, $58.0 \%$ for online reading, $22.2 \%$ for virtual reality, $13.8 \%$ for mobile blog, $11.3 \%$ for submitted jobs, and $9.9 \%$ for podcast. Multimedia as the commonly used network teaching mode can stimulate students' visual and hearing, improving the efficiency of learning. What's more, the use of multimedia as well as activities with other related courses makes it more interactive, and participants are able to know the effect of their learning. Compared to traditional teaching, multimedia is more intuitive and acceptable. The learning mode of online reading requires that the related reading materials are extensive and case-based.

\section{Mobile network teaching interaction}

The style of interaction in the teaching of mobile network can be mainly divided into the following parts, including $58.5 \%$ for resource sharing, $55.1 \%$ for on-line answering, $49.2 \%$ for online discussion and $30.5 \%$ for message board. Whether it is real-time interactive mode or non-real-time interactive mode has been popular with many people. For the real-time interactive mode, online discussion and on-line answering are important ways for students to interact with teachers and other students to enable the interaction between the two sides to communicate and solve problems related to teaching issues in the first place. For the non-real-time interactive mode, it is a message board, which enables students to ask teachers for help after class. Another resource sharing is the supplement to the teaching content and extension of the teaching content where teachers share teaching resources related to teaching content with students to enhance after-school interaction and improvement.

In terms of interactive teaching mode, $77.1 \%$ of people prefer the interactive mode between the individual teacher and different groups of students, while $47.5 \%$ of people like the interactive mode between one teacher and one student. The data indicated that students are more willing to accept the interactive teaching mode that teachers involved in. From the perspective of participation, the participation in a mobile way is better than traditional networks, thus is more efficient. Most of the students say self-control abilities are their common problems occurred in the process of learning, while we need to consider how to eliminate the problem of poor self-control ability caused by external temptation in the set of mobile network teaching platform in addition to the learner's own problems. 
The evaluation on interactive teaching is subjective, including the evaluation on frequency of interaction, the length of interaction time and the number of interaction. Compared with the traditional network teaching, mobile network teaching has fewer restrictions, and because of their own imperfections, so the evaluation on mobile network teaching is average. Mobile network teaching has a strong potential for development, so teachers and students take great initiative to get involved in. The last one is the effect of interaction, which is difficult to be evaluated by the subjective, while in general the effect of mobile network teaching is better than traditional teaching.

\section{EVALUATION SYSTEM CONSTRUCTION}

Currently there are many academic researches on the evaluation method, whether theoretical research or specific evaluation method has a very detailed and in-depth study. However, there are few researches on the evaluation system of teacher-student interactive teaching mode on network teaching platform, and the only research is about some subjects. However, interactive teaching and traditional teaching also have a lot in common and people need to extract common and its special place to integrate them into the evaluation system. According to the characteristics of interactive teaching to establish evaluation indicators, and then use the traditional evaluation methods to evaluate. Frequently-used evaluation methods include analytical hierarchy process, fuzzy comprehensive evaluation method and factor analysis, especially analytical hierarchy process and fuzzy comprehensive evaluation method, which are widely used in the evaluation of teaching quality. In addition, the commonly used evaluation methods are as follow: 1) Method for establishing classroom teaching quality evaluation system: target decomposition method, multivariate statistical method, connotation analysis, questionnaire survey and literature review, etc; 2) Method of determining weights: expert meeting method, analytical hierarchy process and Delphi measure, etc. Whether it is to establish the index system or to determine the weight, methods are diverse, and only by choosing the right method can we make the evaluation result more objective and scientific.

For the use of mobile network teaching platform, teachers and students' activities are no longer face-to-face teaching and learning, instead teachers upload data, video, homework problems or even a web site link, and then students download and learn such shared resources and interact with their teachers. While the use of the mobile network platform leads to the traditional education evaluation index no longer a reference, or the reference value is very low and the result of indicator measure is not convincing [7].

Due to the fact that the teaching process of mobile network teaching platform cannot be fully observed and evaluated, so the evaluation system of the mobile network teaching platform is more evaluation of the teaching effect. In combination with the evaluation index of the network teaching platform being used, the evaluation index framework of mobile network teaching platform has formulated initially. Here is the evaluation index framework of mobile network teaching platform (Table 1).

TABLE I EVALUATION FRAMEWORK OF MOBILE NETWORK TEACHING PLATFORM

\begin{tabular}{|c|c|c|}
\hline \multirow{8}{*}{ Teacher } & \multirow[t]{3}{*}{ T1 resource sharing } & $\begin{array}{l}\text { T11 Whether the content of resource sharing is in accordance with the } \\
\text { curriculum }\end{array}$ \\
\hline & & T12 Whether the content of resource sharing is colorful \\
\hline & & T13 Resource sharing is moderately updated \\
\hline & \multirow[t]{3}{*}{ T2 interactive teaching } & T21Frequency of interaction between teachers and students \\
\hline & & T22 Correlation between interactive content and curriculum teaching \\
\hline & & T23 Whether problems can be solved timely and comprehensively \\
\hline & \multirow[t]{2}{*}{ T3 learning effect } & T31Whether achieving desired effect of teaching \\
\hline & & $\begin{array}{l}\text { T32 Whether to stimulate students' interest in learning and improve their } \\
\text { motivations }\end{array}$ \\
\hline \multirow{10}{*}{ Student } & \multirow{4}{*}{$\mathrm{S} 1$ resource sharing } & S11basic principles of sharing resource \\
\hline & & S12 the main point of sharing resource \\
\hline & & S13 Whether sharing resource links with practice \\
\hline & & $\begin{array}{l}\text { S14 Whether sharing resource is in accordance with fragmentation of } \\
\text { learning }\end{array}$ \\
\hline & \multirow[t]{3}{*}{ S2 Learning interaction } & S21Frequency of interaction with teachers and other students \\
\hline & & S22 Correlation between interactive content and curriculum learning \\
\hline & & S23 Whether interaction can be responded timely \\
\hline & \multirow[t]{3}{*}{ S3 learning effect } & S31Master and understand the course knowledge well \\
\hline & & S32 Improve the ability of learning and solving problems \\
\hline & & S33 Encourage to imagine and give inspiration \\
\hline
\end{tabular}

Evaluation is the first judge an object, drawing a conclusion, and to take some measures according to the conclusions to make the object to meet or close to the standard of judgment. Mutual evaluation between teachers and students is to judge a teacher or a student to see whether he is a good teacher or a student. If not, how to improve so as to achieve standards of excellence. It is generally recognized that outstanding students will have better performance eventually in the usual learning.
For example, students with good academic performance will have better performance in the normal course of learning. So we can do research on outstanding students based on this survey to conclude how long will they spend on mobile network teaching platform during their usual time, and to get the long-run average of outstanding students so as to know which level can be considered "outstanding" [8]. 
In the formulation of evaluation criteria, the survey respondents include each type of school teachers and students, and the survey respondents are divided into "excellent", "good" and "general" according to the results of the questionnaire (Note: The investigation should be non-real name and the result shouldn't be disclosed to the survey respondents; The investigation of the use of the mobile network teaching platform for all kinds of people found the standard of "excellent", "good" and "general" about the mobile network teaching platform. For example, the survey results show the average value of the frequency of the use of mobile network teaching platform is "3 times / day" for "excellent students", then " 3 times / day" is the standard of excellent students.)

In practice, however, due to various reasons statistical results is a decimal value, such as 3.2 times / day, which is an ambitious value, while 3-4 times / day is a better choice (This range belongs to $68.26 \%$ outstanding students who rank near the top, which obeys normal distribution). Similar qualitative results can be performed like this, for example, "good", "general", "bad" can be compared to "80-100", "60-80", "060 ", and it can still get a good standard range.

The correlation coefficient method is used to get the weight of each index. According to the final statistical results, the correlation coefficient of each index is obtained, and the weight of each index is obtained. Finally, the evaluation index value can be obtained according to the performance of a student in the mobile network teaching platform and multiplied by its weight, and compared the results with standard to conclude the learning situation of the student is outstanding.

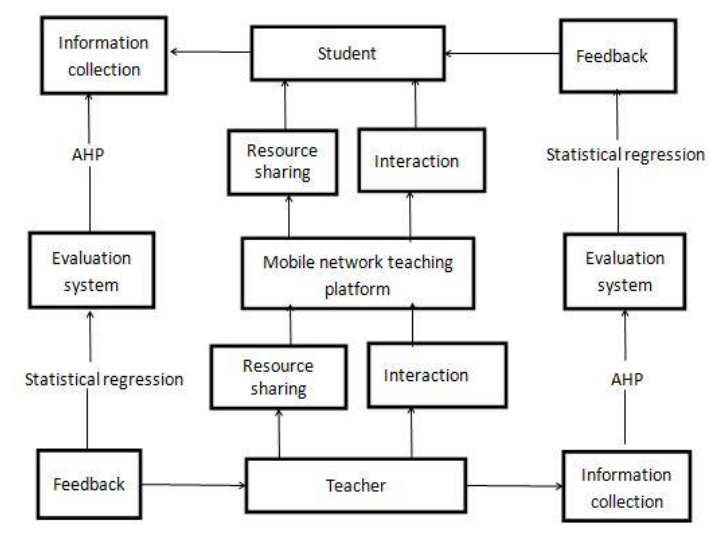

Fig. 3. Mobile network evaluation system

Due to the fact that the definition of excellent students is more affected by traditional education, there are few errors with the initial model. In later practice, it is necessary to collect the data of outstanding students' performance on the network teaching platform, and to regain the new standard, reducing the influence of traditional educational factors on mobile network teaching platform.

\section{CONCLUSION}

Mobile network teaching using emerging technologies will adapt to the way of learning in the future, which has broad application prospects. In the network environment, the increase of the amount of data increases the learning materials needed by the students, and the mobile network makes the learning materials more easily available, which has a very important influence and effect on the students' learning efficiency. As the mobile network technology is just getting started, whose hardware and software have room for further development, while how to realize facilitation and personification is still a problem needed to improve, and mobile network speed, stability and software efficiency affect efficiency of learning and even learning initiative. Nowadays the teaching interaction based on mobile network should take into the following points into consideration:

(1) Personalized learning: This is based on the unique advantages of mobile network teaching model, and it is the new direction for future learning. Personalized learning is based on students' spare capacity and self-learning ability. Only the personalized learning can really improve student learning efficiency.

(2) Modular knowledge: The selection and arrangement of network courses as the main part of mobile network teaching will directly affect the effect of interactive teaching with students. Mobile network teaching differs from traditional classroom teaching, and courses will be modularized, divided in the mobile network teaching. Besides the mobile network, teaching shortens teaching time, and the teaching mode of knowledge point widely used.

(3) Interest-oriented guidance: In the mobile network teaching mode, students use the scattered time to study, which requires mobile network teaching to constantly increase the consistency of interest points to guide students to learn knowledge according to their interest.

(4) Controllable progress: Teaching based on the mobile network requires students to control their own learning process, while how to control their own progress and degree of learning is difficult. Increasing the control function through technical methods can not only help students know their learning progress but also help teachers to master the students' learning progress. What's more the incentive mechanism should be created to improve students' learning motivation.

\section{REFERENCES}

[1] Zhu, Cui E. "Research on Teacher-student Interactive Teaching In Network" [D]. Hu Nan: Hunan Normal University, 2010. (in Chinese)

[2] Liang, Lin Mei etc. "A Survey Report on the Status of Online Teaching in Higher Education: Case Study of Instructors from Universities of Nanjing ". Open Education Research[J], 2013.(in Chinese)

[3] Zhang, Hai Shui. "Practice and Thinking of Multimedia Teaching in Network Teaching environment". Education Moderation[J]. Volume 02, 2014. (in Chinese)

[4] Wang, Qiu Yue. 'Essence and application of 'MOOCS' 'MCOV' and 'FC' ". Shanghai Research on Education[J]. Volume 08, 2014. (in Chinese)

[5] Cai, Xue Lian . "Study on Multi - dimensional Interactive Teaching Mode Based on High Quality Course Platform"[D]. Fujian Normal University2013. (in Chinese)

[6] Liang Peng,Wenming Dong, Yiding Ge. "Interactive Teaching in Multiple-media", Modern Education[J]. July 2015.(in Chinese)

[7] Weiming Zhang, Yi Dai. "Localization of Interactive Teaching in Cloud Computing", IT in Education[J]. Volume 2, 2015.(in Chinese)

[8] MOE of China.Education IT Standard CELTS-22, 2002.(in Chinese) 